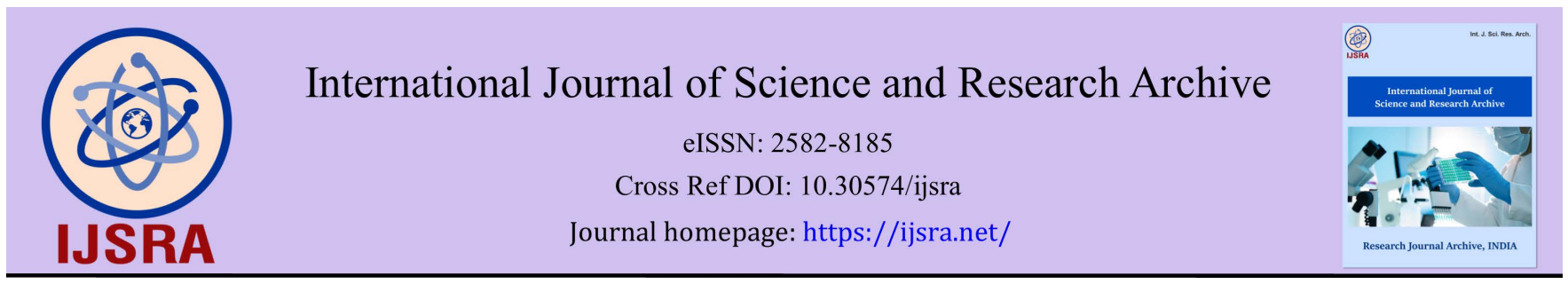

(RESEARCH ARTICLE)

Check for updates

\title{
How popular is X-ray hysterosalpingography in the investigation of infertility by radiographers and radiologists in Nigeria?
}

\author{
Adebayo Jamiu Isiaq 1,2*, Chukwuemeka Christopher Ohagwu 2, Jovita Ada Daniel ${ }^{3}$, Kelechi Kyrian Okwara \\ 4 , and Tobenna Henry Okafor 5 \\ ${ }_{1}^{1}$ Postgraduate School, Nnamdi Azikiwe University, Awka, (Nnewi Campus), Nigeria \\ 2 Department of Radiography \& Radiological Sciences, Nnamdi Azikiwe University, Awka, (Nnewi Campus), Nigeria. \\ 3 Department of Prosthetics \& Orthotics, Federal University of Technology, Owerri, Nigeria. \\ ${ }^{4}$ Radiology Department, Lagos State University Teaching Hospital, Ikeja, Nigeria. \\ ${ }^{5}$ Department of Radiography, Federal University of Technology, Owerri, Nigeria.
}

International Journal of Science and Research Archive, 2021, 02(02), 206-210

Publication history: Received on 20 April 2021; revised on 29 May 2021; accepted on 01 June 2021

Article DOI: https://doi.org/10.30574/ijsra.2021.2.2.0076

\begin{abstract}
Background: Nigeria has an infertility rate of $4 \%$ to $48.1 \%$. This health condition is the most frequently investigated in radiology departments across the country. Although ultrasound is used as first line investigation, its limited sensitivity to tubal patency has made hysterosalpingography (HSG), despite its radiation risks, as the procedure of choice.

Objective: To determine the throughput of all special investigations in the study locations with a view to ascertaining if the use of hysterosalpingography is declining or flourishing.

Methods: A retrospective extraction of data about special investigations from physical archives in the radiology department of two tertiary hospitals. Concluded special investigations between 2012 - 2014 and 2017 - 2019 were enlisted. The physical film jackets in both centers were consecutively scrutinized and the type and date of special investigation was noted.

Results: A total of one hundred and forty-eight thousand, three hundred and twenty-two $(148,322)$ patients aged 2 days to 95 years (mean: $34.85 \pm 16.61$ years) passed through the radiology departments between $2012-2014$, and 2017 - 2019. Those for special radiological investigations numbered 4,806 (3.24 \%). Hysterosalpingography (n = 2.148; $44.7 \%)$ and lateral invertogram $(\mathrm{n}=39 ; 0.8 \%)$ were the special investigations with the highest and least throughputs, respectively. There were five specific HSG findings and fibroid had the highest frequency $(n=683 ; 31.80 \%)$.
\end{abstract}

Conclusions: Hysterosalpingography is the most common special radiological procedure for investigating infertility by radiographers and radiologists in Nigeria.

Keywords: Infertility; Hysterosalpingography; Fibroid; Radiographer; Radiologist

\section{Introduction}

Infertility is a major public health problem globally, and the key reason for it in females is blockage of fallopian tubes due to infections [1]. Secondary infertility is more common than primary, and this is suggestive of post-abortion and post-partum infections [2]. In Africa, especially in Nigeria with about 200 million persons, a population considered to be the highest from any single country on the continent [3], fertility is greatly cherished. Infertility is therefore, viewed

\footnotetext{
* Corresponding author: Adebayo Jamiu Isiaq ; +2348086075040; E-mail: jamiudele@yahoo.com

Postgraduate School, Dept. of Radiography \& Radiological Sciences, Nnamdi Azikiwe University, Awka, (Nnewi Campus), Nigeria. Copyright (C) 2021 Author(s) retain the copyright of this article. This article is published under the terms of the Creative Commons Attribution Liscense 4.0.
} 
with displeasure by the citizens and seen by the victim as personal tragedy. This may lead to depression, stigmatization, marital instability, and enormous psychological stress $[2,4,5]$.

South East Asia and Sub-Saharan African countries are noted to have the highest prevalence of infertility [1], with Nigerian figure being put at a range of $4 \%$ to $48.1 \%$ [5, 6]. In Radiology departments in the country, infertility is the special investigation with the highest throughput, and with ultrasound being the modality of choice for first line investigation [7]. Although ultrasound is sensitive for masses in the genital tract, it has limited sensitivity and specificity for tubal patency [8]. Hysterosalpingography (HSG) however, has high sensitivity and specificity for tubal patency [4, 9], although it carries inherent radiation risks [10]. Sensitivity measures the number of people who truly have the disease who test positive, whereas specificity measures the number of people who do not have the disease who test negative [2].

Regular special x-ray investigations carried out in Nigeria include intra-venous urography (IVU), gastrointestinal tract contrast studies, colostography, lateral invertogram, micturating cysto-urethrography (MCUG) and retrograde urethrocystography (RUCG), and hysterosalpingography (HSG). Of these, only HSG is limited to investigation of infertility [7]. Hysterosalpingography (HSG) is performed during the early proliferative phase of the menstrual cycle when the endometrium is thin and clearly visualizable. The probability of ovulation and pregnancy at that phase is also minimal. The patient is placed in the lithotomy position on the x-ray couch and with an angle poise lamp providing illumination. Tablet Hyosine 10mg (Buscopan) is given 30 minutes before the procedure to minimize pain and to avoid any spasm in the fallopian tubes.

A speculum is used to part the labia majora and minora in order to reveal the cervical os, which is then swabbed with antiseptic solution. The external os is then cannulated using Leech Wilkinson cannula, or 6Fr Foley's catheter. A forcep may be used to clamp the anterior or lateral wall of the cervix to prevent prolapse during contrast injection. A radiopaque contrast media, preferably non-ionic, is then slowly injected with gentle pressure, under fluoroscopic control, using a volume of about $10 \mathrm{ml}$ which is sufficient to fill, but not to overdistend the uterine cavity. Simultaneously, $\mathrm{x}$-ray exposures of the pelvis are made in supine position $[2,11]$.

Despite the quality and quantity of personnel and x-ray machines deployed for several special radiological procedures in both facilities, staff were often overwhelmed with the volume of examinations. This aroused the curiosity of the researchers to investigate the throughput of special procedures with a view to present empirical data for cost-effective patient scheduling.

\section{Material and methods}

The work was a retrospective extraction of records of completed special investigations at two different periods and at two sister teaching hospitals. The first extraction was carried out at the first teaching hospital in 2014 and involved examinations done between 2012 - 2014, with conventional film-screen radiography. The second extraction was done in 2019 at the second teaching hospital and involved examinations carried out from April 2017 to April 2019 under fluoroscopic guidance. Each special procedure was carried out by a team comprising radiographers, radiologists and nurses. No record was excluded. The physical film jackets in both centres were consecutively scrutinized and the date and type of special investigation was noted.

\subsection{Study locations}

Both of the teaching hospitals had much in common. They were both located in Southern Nigeria, were governmentowned and were over two decades old. Staff strength was $\geq 2000$ with personnel from radiology department being less than $5 \%$ at each centre. They also served as training hospitals for interns in radiography and residents in radiology [10].

\subsection{Equipment}

Both centres were well-equipped with basic and moderately sophisticated imaging modalities and thus enjoyed medical tourism from contiguous states. There were ultrasound scanners; x-ray technologies of film-screen Radiography (FSR), Computed Radiography (CR) and Direct Digital Radiography (DDR); mammography machine; fluoroscopy machine; Computed Tomography (CT); and Magnetic Resonance Imaging (MRI) scanner [7]. 


\section{Results}

A total of 148,322 patients aged 2 days to 95 years (mean: $34.85 \pm 16.61$ ) passed through the radiology departments between 2012 - 2014, and 2017 - 2019. Those for special radiological investigations numbered 4,806 (3.24\%). This is shown in Table 1.

Table 1 Demographic characteristics of patients

\begin{tabular}{|l|c|c|c|}
\hline \multicolumn{1}{|c|}{ Parameter } & $\begin{array}{c}\text { Centre A } \\
(\mathbf{2 0 1 2}-\mathbf{2 0 1 4})\end{array}$ & $\begin{array}{c}\text { Centre B } \\
\mathbf{( 2 0 1 7}-\mathbf{2 0 1 9})\end{array}$ & Total \\
\hline Total throughput of patients in the department & $70,210(47.3 \%)$ & $78,112(52.7 \%)$ & 148,322 \\
\hline Total throughput for x-ray special investigations & 2,340 & 2,466 & $4,806(3.24 \%)$ \\
\hline Age range of patients & 2 days -95 years & 2 days -84 years & 2 days - 95 years \\
\hline Mean \pm SD (years) & $34.70 \pm 17.81$ & $32.30 \pm 15.30$ & $34.85 \pm 16.61$ \\
\hline
\end{tabular}

A look at Table 2 indicates that Hysterosalpingography $(n=2,148 ; 44.7 \%)$ and lateral invertogram $(n=39 ; 0.8 \%)$ were the special investigations with the highest and least frequencies, respectively: The two facilities generally carried out six special investigations disproportionately

Table 2 Throughput of special investigations

\begin{tabular}{|l|c|c|}
\hline Age (years) & Total & Percentage (\%) \\
\hline HSG & 2,148 & 44.7 \\
\hline IVU & 1,379 & 28.7 \\
\hline MCUG \& RUCG & 928 & 19.3 \\
\hline GIT studies & 216 & 4.5 \\
\hline Colostography & 96 & 2.0 \\
\hline Lateral invertogram & 39 & 0.8 \\
\hline Total & 4,806 & 100.0 \\
\hline
\end{tabular}

As shown in Table 3, there were five specific findings at HSG with fibroid having the highest frequency $(n=683,31.80 \%)$.

Table 3 Hysterosalpingography (HSG) findings

\begin{tabular}{|l|c|c|}
\hline Parameters & Frequency & Percentage \\
\hline Fibroids & 683 & 31.80 \\
\hline Occlusion & 548 & 25.50 \\
\hline Adhesions & 483 & 22.50 \\
\hline Hydrosalpinx & 352 & 16.40 \\
\hline Congenital anomalies & 82 & 3.80 \\
\hline Gross total & 2,148 & 100.00 \\
\hline
\end{tabular}




\section{Discussions}

The study analyzed records of 148,322 patients who passed through the radiology departments of two busy teaching hospitals in Nigeria between 2012 - 2014, and 2017 - 2019. It aimed to determine the specific number of those who were for special investigations and which was the most common investigation. Patients were aged 2 days to 95 years with mean age of $34.85 \pm 16.61$ years.

Our findings indicate that both centres contributed an almost similar number of throughput of patients to the pool $(\mathrm{A}=$ $47.3 \%$; $B=52.7 \%$ ). In addition, the specific special investigations undertaken were hysterosalpingography (HSG), intravenous urography (IVU), micturating cystourethrography (MCUG) and retrograde urethrocystography (RUCG), GIT studies (barium swallow, barium meal and barium enema), colostography and lateral invertogram. From these, it was discovered that hysterosalpingography $(\mathrm{n}=2148 ; 44.7 \%)$ and lateral invertogram $(\mathrm{n}=39 ; 0.8 \%)$ were more common and rare, respectively. Evaluation of infertility with HSG showed that fibroid $(n=683 ; 31.8 \%)$ and congenital anomalies $(\mathrm{n}=82 ; 3.8 \%)$ were the pathologies with the highest and lowest frequencies, respectively.

The mean age from our study (34.85 years) is in agreement with similar studies from the locality [11 - 14], as well as in Pakistan (mean: 30 - 40 years) [2]. A younger mean age (28.9 years) was however, reported by another work in the same locality [5]. The difference may be due to the fact that only HSG patients were under consideration in the differing work whereas a broader spectrum of special investigations was being reviewed in our work. The implication is that HSG patients will be of a certain age range, possibly from 20 - 40 years, while other special investigations will have neonates as well as the very aged [7]. The radiology departments should therefore, be prepared to handle all age range of patients, and be equipped enough with personnel and facilities to give individualized attention to those patients with critical needs.

It is also noteworthy that the highly invasive HSG procedure that also carries radiation risk, is the procedure that tops the list of special investigations in the locality. A total of 2,148 of these were undertaken in two busy hospitals within a four year period $(2012-2014,2017$ - 2019). This number appears low when compared with the fact that within a 9 month period in 2008 in a single hospital in Pakistan, there were 1,124 HSG cases [15]. The sharp drop in number of HSG cases in our locality may be due to the fact that ultrasound is used as the first line of investigation of infertility [8]. Patients referred to HSG after ultrasonography are often those suspected of tubal adhesions, a condition that ultrasound has low specificity for $[11,12]$. Furthermore, teaching hospitals in the locality are equipped with different radiological modalities and these help to reduce the number of cases referred for special investigations [7].

Fibroid (31.80\%) was the most common challenge found on HSG. This is in agreement with another work from the locality [12]. Contrariwise, majority of works see tubal blockage as the single major cause of infertility $[5,11,13,14]$. The discrepancy may be due to the design of the studies. Whereas the two aligning works did not exclude radiographs during enlistment, dissenting works were specific to tubal pathologies. Since HSG is basically for investigation of tubal patency $[11,15]$, future designs may well focus on fallopian tubes.

There were a few limitations in this work. Equipment downtimes which affected throughput did not enable continuous enlistment of subjects from 2012 till date. This may have affected the frequency of patients for special investigations and produced a much lower throughput. Furthermore, challenges in assessing archived reports did not give room for an appropriate comparison of both centers.

\section{Conclusion}

In conclusion, multiple special investigations are carried out in the radiology departments in the locality, and hysterosalpingography (HSG) is the most common special radiological procedure for investigating infertility by radiographers and radiologists in Nigeria.

\section{Compliance with ethical standards}

\section{Acknowledgments}

Our gratitude to clerical staff of the Radiology Departments who helped to retrieve patients' images and reports from archives. 


\section{Disclosure of conflict of interest}

Authors declare that there is no conflict of interest

\section{Statement of ethical approval}

Ethical approval was obtained from the institutional ethical Committee (LASUTH/LREC/06/10/1151).

\section{Statement of informed consent}

Since contact with patients was not part of the design of the study, informed consent was not obtained from them.

\section{References}

[1] Elhussein OG, Ahmed MA, Suliman SO et al. Epidemiology of infertility and characteristics of infertile couples requesting assisted reproduction in a low-resource setting in Africa, Sudan. Fertil Res and Pract. $2019 ; 5: 7$.

[2] Mushtaque S, Aamir MO, Mian A, Shah AR, Saleem H, Rauf S, Iftikhar S. To determine frequency of tubal blockage in infertility patients undergoing x-rays hysterosalpingography. Pakistan Journal of Radiology. 2018; 28(4): 272 -276 .

[3] Adejoh, Thomas. An Inquest into the Quests and Conquests of the Radiography Profession in Nigeria. Journal of Radiography \& Radiation Sciences (JRRS). 2019; 33(1): 1 - 38.

[4] Botwe BO, Bamfo-Quaicoe K, Hunu E, Anim-Sampong S. Hysterosalpingographic findings among Ghanaian women undergoing infertility work-up: a study at the Korle-Bu Teaching Hospital. Fertil Res Pract. 2015 ; 1: 9.

[5] Panti AA, Sununu YT. The profile of infertility in a teaching hospital in North West Nigeria. Sahel Med J. 2014; 17(1): 7-11.

[6] Mohammed-Durosinlorun A, Adze J, Bature S, Abubakar A, Mohammed C, Taingson M, Airede L. Awareness and willingness to adopt among infertile women seen at a tertiary hospital in Northern Nigeria. African Journal for Infertility and Assisted Conception. 2018; 3(1): 10.

[7] Adejoh T, Onwuzu SWI, Luntsi G, Nkubli FB and Ikegwuonu NC. X-Ray Special Investigations Rebook Analysis (XSIRA). IOSR Journal of Dental and Medical Sciences (IOSR-JDMS). 2015; 14(7):71-75.

[8] Eze JC, Ohagwu CC, Ugwuanyi DC, Chiegwu HU, Onyeugbo E. Diagnostic accuracy of ultrasound scans for the diagnosis of pelvic inflammatory disease keeping laboratory high vaginal swab/urine microscopy culture as gold standard in Anambra State, Nigeria. International Journal of Medicine and Medical Sciences. 2018; 10(8): 94-99.

[9] Heis M, Amarin Z, Ibrahim AY, Obeidat N, Omari M. Uterine and tubal anatomical abnormalities in infertile women: diagnosis with routine hysterosalpingography prior to selective laparoscopy. S Afr J Radiol. 2011; 15(4): 120-122.

[10] Adejoh T, Elugwu CH, Ezugwu EE, Sidi M, Aronu ME. A single-centre experience of radiation dose mitigation in computed radiography using dose charts. Pakistan Journal of Radiology. 2020; 30(1): 25 - 33.

[11] Balogun BO, Adegboyega OA, Awosanya GOG. Tubal abnormalities in patients with intrauterine adhesion: Evaluation using hysterosalpingography. Ann Afr Med. 2014; 13(4): 179- 183.

[12] Njoku J, Abonyi LC, Eze CU. Common Hysterosalpingographic Findings in Infertility Cases in Lagos State, Nigeria. Journal of Association of Radiographers of Nigeria. 2012; 26: 1 - 7.

[13] Udobi SI, Aronu ME. Hysterosalpingographic findings in women with infertility in Awka, Anambra State, SouthEast Nigeria. Niger J Surg Sci, 2017; 27: 47-50.

[14] Danfulani M, Mohammed MS, Ahmed SS, Haruna YG. Hysterosalphingographic findings in women with infertility in Sokoto North Western Nigeria. Afr J Med Health Sci. 2014; 13: 19-23.

[15] Naqi S, Shafqat-Ul-Islam S, Raza S, Haroon H. Pattern of pathologies on hysterosalpingography in primary infertility and review of literature. Pakistan Journal of Radiology. 2008; 18(3): 82-86. 